\title{
Field Capacity and Harvest Efficiency Evaluation of Traditional Small Box and Semi-Automated Bin Handling Systems for Wild Blueberries ${ }^{\dagger}$
}

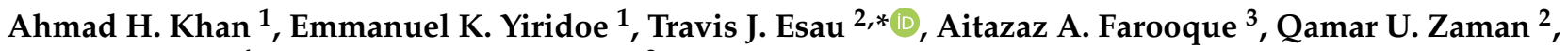 \\ Prosper J. Koto ${ }^{4}$ and Craig B. MacEachern ${ }^{2}$ \\ 1 Department of Business and Social Sciences, Faculty of Agriculture, Dalhousie University, \\ Truro, NS B2N 5E3, Canada; Ahmad.Khan@dal.ca (A.H.K.); emmanuel.yiridoe@dal.ca (E.K.Y.) \\ 2 Department of Engineering, Faculty of Agriculture, Dalhousie University, Truro, NS B2N 5E3, Canada; \\ qzaman@dal.ca (Q.U.Z.); maceachernc@Dal.Ca (C.B.M.) \\ 3 Faculty of Sustainable Design Engineering, University of Prince Edward Island, \\ Charlottetown, PE C1A 4P3, Canada; afarooque@upei.ca \\ 4 Research Methods Unit, Nova Scotia Health Authority, Halifax, NS B3H 2E2, Canada; \\ prosper.koto@nshealth.ca \\ * Correspondence: tesau@dal.ca; Tel.: +1-902-893-3055 \\ + This paper is a part of the master thesis of Ahmad H. Khan, presented at Dalhousie University (Canada).
}

\section{check for} updates

Citation: Khan, A.H.; Yiridoe, E.K.; Esau, T.J.; Farooque, A.A.; Zaman, Q.U.; Koto, P.J.; MacEachern, C.B. Field Capacity and Harvest Efficiency Evaluation of Traditional Small Box and Semi-Automated Bin Handling Systems for Wild Blueberries. Agriculture 2021, 11, 957. https:// doi.org/10.3390/agriculture11100957

Academic Editors: Jin He and

Massimo Cecchini

Received: 20 August 2021

Accepted: 29 September 2021

Published: 2 October 2021

Publisher's Note: MDPI stays neutral with regard to jurisdictional claims in published maps and institutional affiliations.

Copyright: (c) 2021 by the authors. Licensee MDPI, Basel, Switzerland. This article is an open access article distributed under the terms and conditions of the Creative Commons Attribution (CC BY) license (https:/ / creativecommons.org/licenses/by/ $4.0 /)$.
Abstract: Mechanical harvesters with small box and semi-automated bin handling systems are increasingly being used for harvesting wild blueberries in Eastern Canada, and Northeastern, USA. However, their field capacity and performance have not been quantified and compared. Important measures of field capacity and efficiency for a traditional mechanical harvester were compared with a novel semi-automatic bin handling harvester. Data were obtained from on-farm field trials conducted at four sites in Nova Scotia, Canada in 2017 and 2018. Both harvesters had double head configurations, along with other similar engineering configurations: (i) $0.66 \mathrm{~m}$ picking reels; (ii) 16 picker bars per head and 65 teeth per bar; (iii) $1.72 \mathrm{~m}$ picking width; (iv) $21 \mathrm{rpm}$ head speed; and (v) $0.31 \mathrm{~ms}^{-1}$ ground speed. Each harvester was operated for $120 \mathrm{~min}$ and data such as berry harvesting time and box handling time were recorded, with six replications during each year. Statistical methods were used to compare the harvest efficiency of the two mechanical harvesters. Harvest time efficiency was significantly higher for the semi-automatic bin handling technology than for the small box handling technology both in $2017(p<0.001)$, and $2018(p<0.001)$. Weed coverage did not have a significant effect of harvest time in either 2017 ( $p=0.694)$ or $2018(p=0.765)$, though it did significantly affect yield in both 2017 ( $p=0.011)$ and $2018(p=0.045)$. The findings provide useful insights for decision-makers contemplating the choice of harvesting technology to sustain profits from wild blueberry production.

Keywords: automation; efficiency; field capacity; mechanical harvester; mechanization; wild blueberry

\section{Introduction}

Wild blueberries are low growing plants with average height range from 0.10 to $0.16 \mathrm{~m}$ [1]. Wild blueberry production commonly follows a two-year cycle with vegetative growth occurring in the first year, followed by berry formation and harvest in the second year [2]. New shoots begin by developing from dormant buds on underground rhizomes [1] during the vegetative year. Plant stems continue to grow until tip-dieback in July and development of floral buds starts from August until October. Over winter, wild blueberry fields are covered with snow, and plants remain dormant until the floral buds develop in Spring [3]. Flowering starts in May of the fruit year and fruit development continues until harvest in mid to late August. The wild blueberry crop is then pruned by flail mower or burning in early Spring of the vegetative year or late in the fruit year after harvest. This 
is done to improve plant dominance by controlling grass and weed germination and to encourage more vigorous fruit producing stems to emerge in the subsequent year $[1,4]$.

The principal challenges facing wild blueberry producers during harvesting are declining labour availability [5], short harvesting windows [6], high labour wages [7], high overall harvesting costs $[8,9]$ and the over 43,000 ha of harvestable wild blueberry land each year [10]. Seasonal labour for wild blueberry production in Atlantic Canada continues to be in short supply. For wild blueberry production, the farm labour challenges are particularly critical during the short harvesting season, from mid-August through earlySeptember as increased labor is needed to harvest the crop. Further, expansion in wild blueberry area under production, has prompted a need for more efficient berry harvesting systems. Investment in labour saving technologies has the potential to address constraints to further expanding crop hectarage [11] and enhancing worker productivity [12]. Further complicating this issue is the vast differences in harvestable yield between fields which can range from $1000 \mathrm{~kg} \mathrm{ha}^{-1}$ to $8000 \mathrm{~kg} \mathrm{ha}^{-1}[13,14]$. As the harvestable yield increases the harvesting speed must decrease to maintain berry quality which subsequently, increases the total harvest time. Increased adoption of mechanical harvesters has the potential to reduce overall cost of production and save time compared with less efficient alternatives such as manual hand raking [4].

Doug Bragg Enterprises (DBE) are the only large-scale producer of wild blueberry harvesters in the world with over 1500 operational today [15]. Over the past few years, they have been designing and implementing a semi-automatic bin handling system for their harvesters which utilizes hydraulics to fill and offload blueberry storage bins. This new system was designed to replace their traditional small box handling system. A comparison of the primary components of each system can be observed in Table 1, and an image of each system can be observed in Figure 1.

Table 1. Comparison of major characteristics of harvesters with alternative handling systems.

\begin{tabular}{|c|c|c|}
\hline $\begin{array}{l}\text { Handling System } \\
\text { Components }\end{array}$ & Small Box Handling System & $\begin{array}{l}\text { Semi-Automatic Bin } \\
\text { Handling System }\end{array}$ \\
\hline Tractor & \multicolumn{2}{|c|}{ Minimum 75-kilowatt $(\mathrm{kW})$ farm tractor } \\
\hline & \multicolumn{2}{|c|}{$0.66 \mathrm{~m}$ picking head } \\
\hline & \multicolumn{2}{|c|}{16 picker bars per head } \\
\hline Harvester configuration & \multicolumn{2}{|c|}{65 picker teeth per bar } \\
\hline & \multicolumn{2}{|c|}{$0.86 \mathrm{~m}$ wide swath width per head } \\
\hline & \multicolumn{2}{|c|}{ Double head configuration (1.72 m effective picking width) } \\
\hline Debris removal method & Blower fan & $\begin{array}{c}\text { Blower fan with wind flow } \\
\text { isolator }\end{array}$ \\
\hline Box stacking and loading & $\begin{array}{l}\text { Rear platform for manual } \\
\text { stacking of boxes }\end{array}$ & $\begin{array}{c}\text { Hydraulic rear handling } \\
\text { system operated by tractor } \\
\text { operator }\end{array}$ \\
\hline \multirow{2}{*}{$\begin{array}{c}\text { Box loading/unloading } \\
\text { Empty box weight } \\
\text { Average weight of berry filled }\end{array}$} & Manual labour & Loader tractor with forks \\
\hline & $1.36 \mathrm{~kg}$ & $30 \mathrm{~kg}$ \\
\hline $\begin{array}{c}\text { Average weight of berry filled } \\
\text { boxes }\end{array}$ & $12 \mathrm{~kg}$ & $136 \mathrm{~kg}$ \\
\hline
\end{tabular}




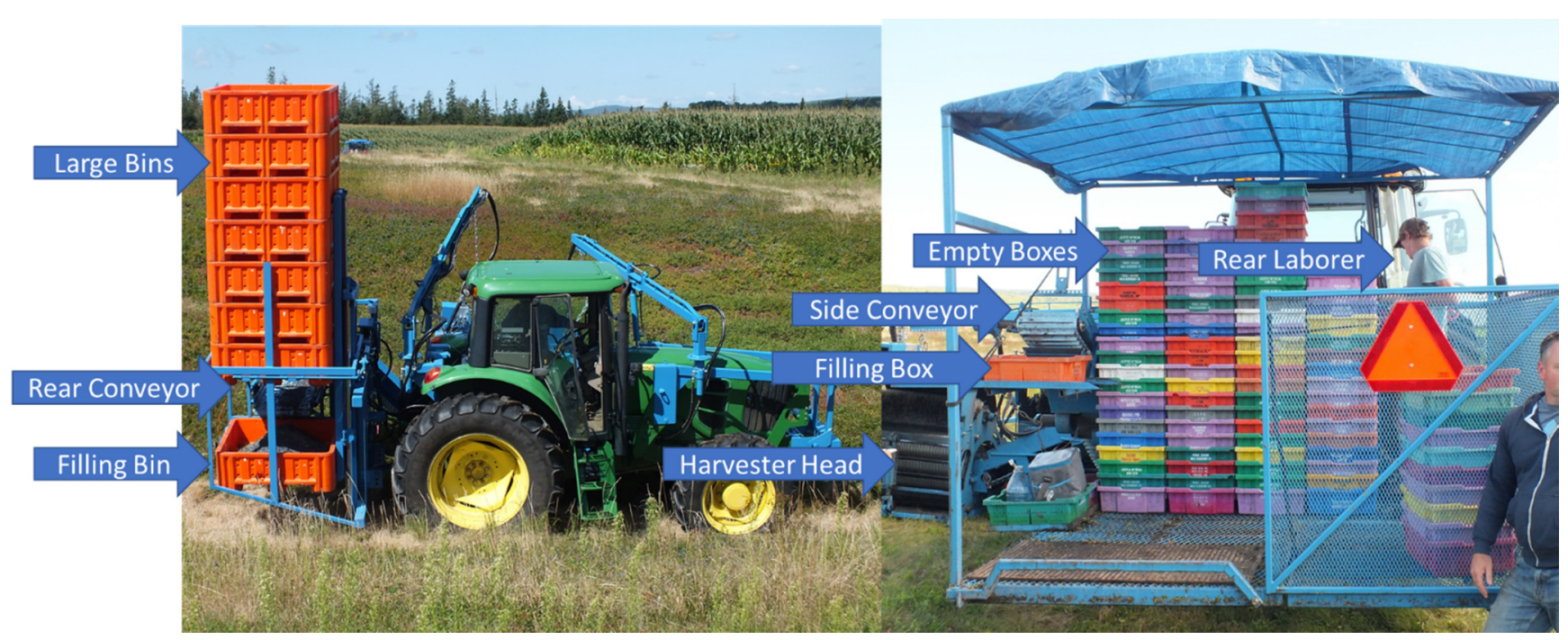

Figure 1. Image of semi-automated bin handling system (left) and small box handling system (right) on.

\section{Doug Bragg Enterprises (DBE) Wild Blueberry Harvesters}

The semi-automated bin handling system is pitched as being more efficient from both a cost and time savings perspective when compared with DBE's traditional small box handling system [15]. The semi-automated bin handling system eliminates the need for a second laborer to manually fill and change boxes and reduces the number of stoppages needed to load and offload boxes. This should all lead to improved field harvest efficiency in terms of area harvested per unit time. Akin to both systems is the harvesting mechanism in which, the reel of the picker head rotates common to the direction of the moving tractor. Comb type picking bars rake the berries from low growing plants and deposit them onto a side conveyer which move the berries toward the rear of the harvester. A blower fan removes debris at the end of the side conveyor. For the small box system, berries are collected by a laborer at this point. For the bin handling system, berries fall onto a rear conveyor which transport the berries to the large bins at the rear of the harvester. A process diagram for both systems can be seen in Figure 2.

Despite the potential efficiency improvements, the semi-automatic bin handling system comes at additional equipment cost compared with the small box handling system. That said, the increased cost associated with upgrading to the semi-automatic bin handling system may be offset by labour savings, and overall increased field harvest efficiency which could prove to justify the cost. Economics of the two handling systems were analyzed by Khan et al. 2020 [16]. The major takeaway from this work demonstrated a difference in net profit between the two systems of CAD\$674 ha ${ }^{-1}$ in 2017 under high yield conditions and CAD $\$ 175 \mathrm{ha}^{-1}$ under lower yielding conditions.

Performance of harvesters with the two handling systems have never previously been quantified and compared. Specifically, their performance in terms of harvest rate, field capacity and efficiency, have not been evaluated. Technical information on wild blueberry harvester field capacity is critical for optimizing production and management operations including scheduling field operations, optimizing farm labour use, and estimating berry harvesting cost and overall cost of production. Producers can enhance profit margins by adopting more efficient harvesting systems and the results of this study will be critical for growers when making this determination.

Studies have evaluated various mechanical harvesters for selected crops by quantifying and comparing several aspects of harvesting operations including harvest time and handling time $[17,18]$, harvest rate $[19,20]$, and field efficiency $[21,22]$. Harvest time and rate are important components of harvesting operations as producers often have limited time to harvest their crop. Field efficiency is also an important determinant of the performance of the harvester handling systems. In wild blueberries, this metric is often influenced 
by topography and fruit density as well as harvester handling parameters. Technical information on the components of total harvest time (especially when decomposed into harvest time and handling time) and harvest rate for wild blueberry mechanical harvesters are important and of interest to wild blueberry farmers and harvester manufacturers. This data has never been quantified and results can lay the groundwork for further harvester efficiency improvements in the long run while providing significant short-term benefits for growers.

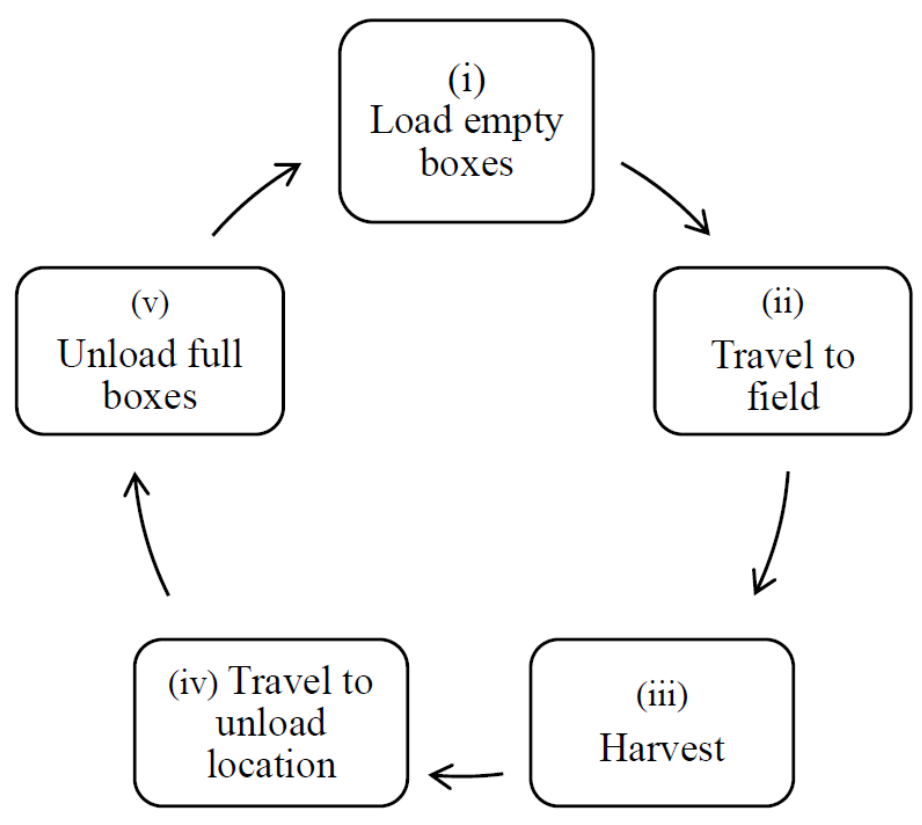

(a) Harvest operation using small box handling system

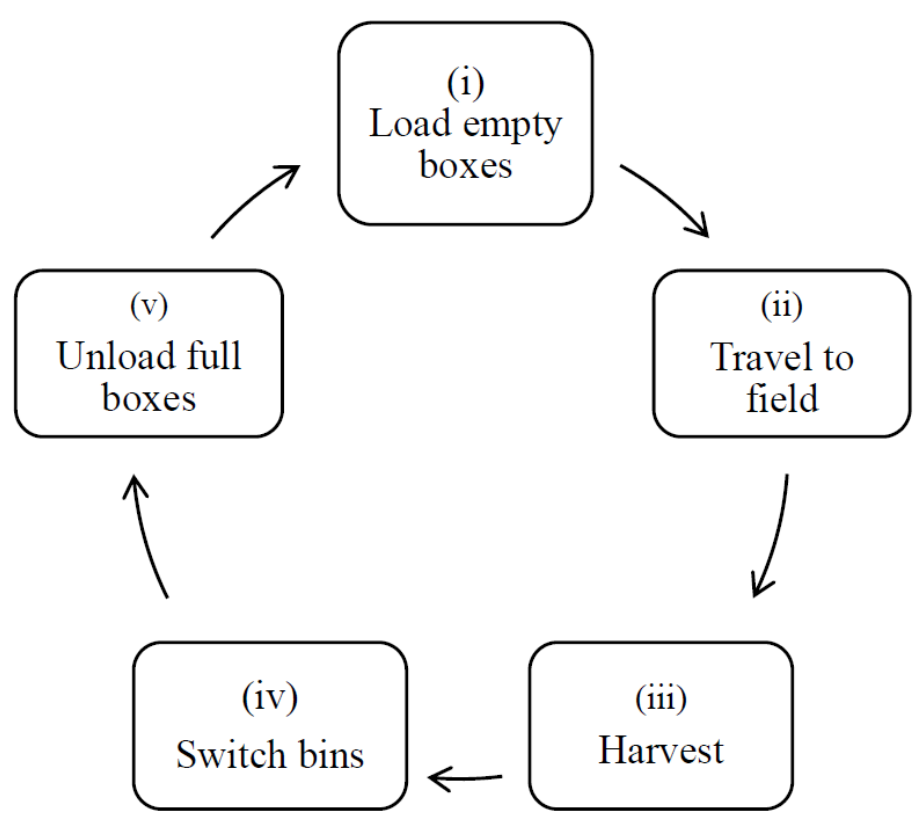

(b) Harvest operation using semi-automated hydraulic bin handling system

Figure 2. Process diagram for the small box handling system (a) and the large bin handling system (b). 
The objective of this study was to quantify and compare the harvest efficiency of wild blueberry mechanical harvesters with both the small box handling system and the semiautomated bin handling system under actual harvesting conditions. The first objective was to quantify, decompose, and compare machine harvest time and berry handling times of mechanical harvesters with the two box handling systems. Handling time was explicitly decomposed into box loading time and unloading time. The second objective was to quantify and compare harvest rate of the small box handling system with similar parameters for the semi-automatic bin handling system. This novel study to assess wild blueberry harvester efficiency will have the ultimate benefit of providing growers with the tools necessary to make an informed decision on whether to upgrade their harvesters. It will also lay the groundwork for further innovation of wild blueberry harvesters by providing critical harvesting and handling data.

\section{Materials and Methods}

\subsection{Study Fields}

Field harvesting trials were conducted during 2017 and 2018. In 2017, field trials were conducted on a five-hectare fruit field in central Nova Scotia, Canada $\left(45^{\circ} 42^{\prime} 65.59^{\prime \prime} \mathrm{N}\right.$, $-63^{\circ} 49^{\prime} 66.56^{\prime \prime} \mathrm{W}$, 5-hectare field) near Debert (Figure 3). In-field investigation into harvesting operations allowed for compiling data that reflects actual cropping conditions. The field trials were conducted on 27 and 28 August 2017. The harvesters fitted with the small box handling and semi-automatic bin handling systems were operated by different harvester operators with similar skill and experience.

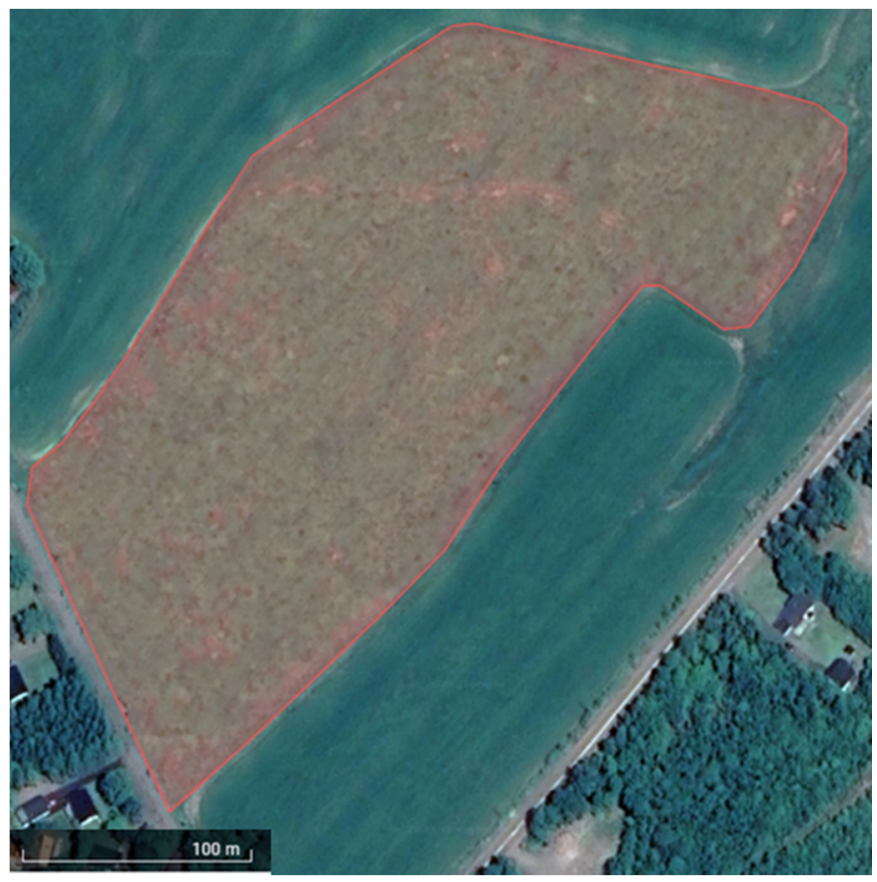

Figure 3. Boundary map for Debert field.

In 2018, field experiments were conducted in two wild blueberry fields in Portapique $\left(45^{\circ} 40^{\prime} 88.79^{\prime \prime} \mathrm{N},-63^{\circ} 72^{\prime} 35.65^{\prime \prime} \mathrm{W}\right.$, 2-hectare section of field) and Antigonish $\left(45^{\circ} 55^{\prime} 71.51^{\prime \prime} \mathrm{N},-61^{\circ} 72^{\prime} 61.77^{\prime \prime} \mathrm{W}, 2\right.$-hectare section of field), Nova Scotia (Figure 4). Field harvesting trials were carried out on 19 and 20 August 2018 in Portapique and 23 and 24 August 2018 in Antigonish. 

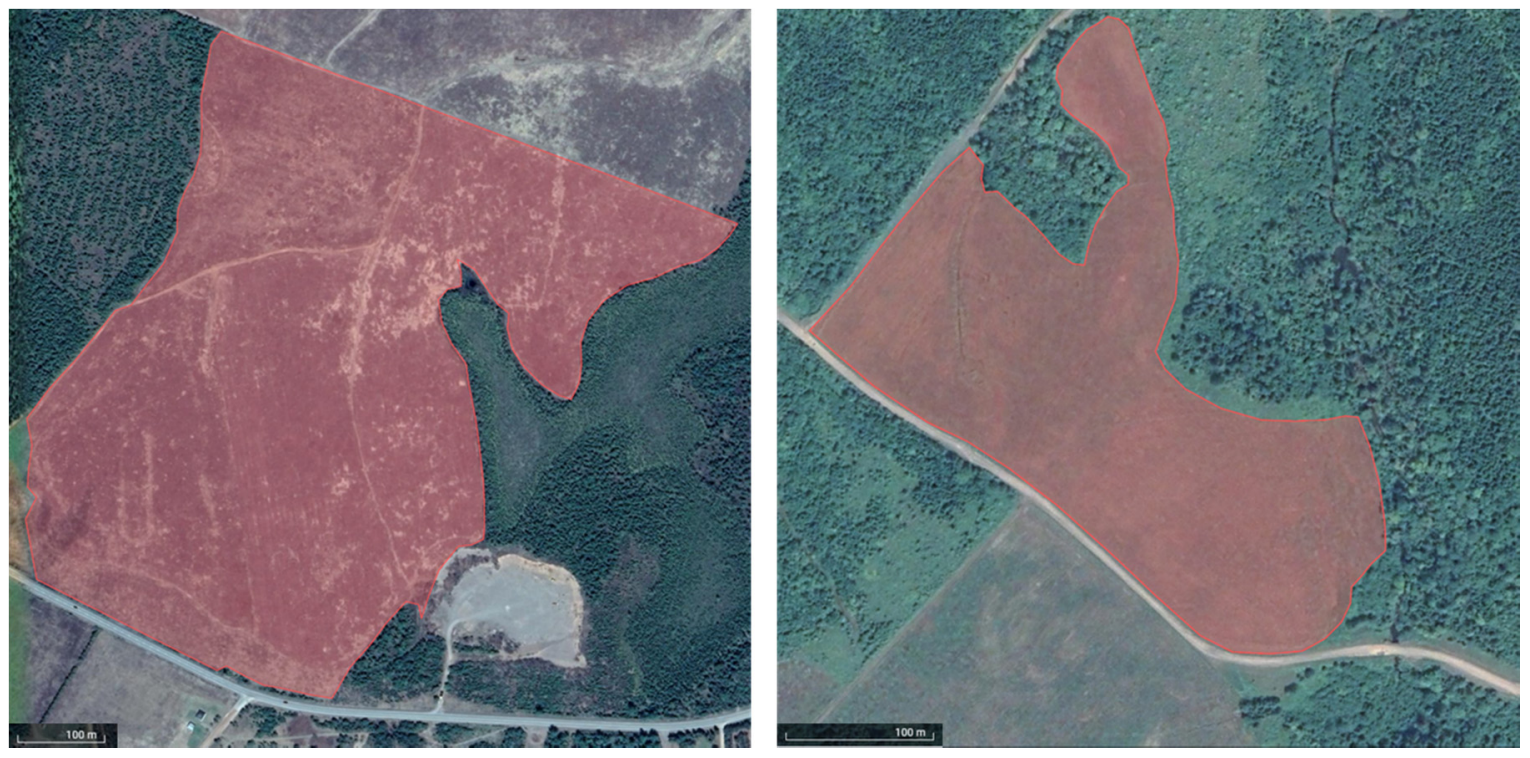

Figure 4. Boundary maps for Portapique (left) and Antigonish (right) fields.

For each of the fields studied in both years, recommended agronomic and management practices were implemented over the past decade, including herbicides, fungicides, insecticides, induced pollination, and mechanical pruning. That said, berry production throughout the Maritimes was affected by frost damage in 2018 [8] resulting in significant reduction in harvestable fruit compared with 2017. During each of the harvesting dates, conditions were similarly sunny and dry. Weather conditions for each of the harvest sites and dates can be observed in Table 2 .

Table 2. Weather data for each of the sites and harvest dates used in this study.

\begin{tabular}{ccccccc}
\hline Fields & \multicolumn{2}{c}{ Debert } & \multicolumn{2}{c}{ Portapique } & \multicolumn{2}{c}{ Antigonish } \\
\hline Sampling dates & 27 August 2017 & 28 August 2017 & 19 August 2018 & 20 August 2018 & 23 August 2018 & 24 August 2018 \\
\hline $\begin{array}{c}\text { Minimum } \\
\text { temperature, }{ }^{\circ} \mathrm{C}\end{array}$ & 8.3 & 5.6 & 15.0 & 12.0 & 18.0 & 13.0 \\
$\quad \begin{array}{c}\text { Maximum } \\
\text { temperature, }{ }^{\circ} \mathrm{C}\end{array}$ & 20.4 & 22.8 & 23.0 & 24.0 & 27.0 & 25.0 \\
$\quad \begin{array}{c}\text { Mean } \\
\text { temperature, }{ }^{\circ} \mathrm{C}\end{array}$ & 14.4 & 14.2 & 19.0 & 18.0 & 22.5 & 19.0 \\
$\quad$ Rain, mm & 0.0 & 0.0 & 0.3 & 0.0 & 0.1 & 0.0 \\
\hline
\end{tabular}

\subsection{Description of Mechanical Harvesters}

In this study, a mechanical harvester with small box handling system was operated with a $100 \mathrm{~kW}$ tractor while an $82 \mathrm{~kW}$ tractor was used for the semi-automatic bin handling system. A $48 \mathrm{~kW}$ loader tractor was also used in both years for loading and unloading the large bins. The two harvester systems were fitted with double-head harvester configurations with a $1.72 \mathrm{~m}$ effective picking width. Both harvester heads had a similar configuration of $0.66 \mathrm{~m}$ (diameter) picking reel, 16 picker bars and 65 tooth configurations (Table 1). Both harvesters were operated at a ground speed of $0.31 \mathrm{~m} \mathrm{~s}^{-1}$ and head speed of $21 \mathrm{rpm}$.

\subsection{Analyzed Parameters}

The two primary methods used for comparing the two harvesting systems were harvest time and harvest rate. Harvest time was defined as the time in which the harvester is actively harvesting fruit over a two-hour period. The component of time in which the harvester was not harvesting fruit during the two-hour period was defined as handling 
time. Handling time for the small box system is the time to travel to the unloading location on the edge of the field, the time to return to the picking location and the period in which boxes are being loaded and unloaded from the harvester. Handling time for the semiautomated bin system is the period in which bins are being loaded and unloaded only as full bins are dropped in field and picked up by a second tractor with this system.

Harvest rate was defined in hours per hectare [23] and is represented by Equation (1) [24]:

$$
H R=\frac{2.78}{S * W * F E}
$$

where $H R$ is the harvest rate $\left(\mathrm{h} \mathrm{ha}^{-1}\right), S$ is the average speed of the operating harvester $\left(\mathrm{m} \mathrm{s}^{-1}\right), W$ is the working width of the harvesters picking heads $(\mathrm{m})$ and FE is the field efficiency (unitless). The constant 2.78 was determined by dividing the number of square meters in a hectare by the number of seconds in an hour [24]. Field efficiency was calculated by dividing the total harvesting time by the total time (harvesting plus handling). In each of the analyses, speed was maintained at a constant $0.31 \mathrm{~m} \mathrm{~s}^{-1}$ and a working width of $1.72 \mathrm{~m}$ was used on both harvesters.

\subsection{Experimental Design}

Data collected from 2017 and 2018 had to be analyzed separately due to the significant difference in harvestable yield resulting from the late frost event of 2018 [8] and the usage of multiple fields in 2018. Multiple fields had to be used in 2018 due to limitations in equipment accessibility and an inability to test both systems in the same field.

A Completely Randomized Design (CRD) was used to compare the difference in harvest time and rate between the small box handling system and the semi-automated bin handling system. Each harvester was operated for two hours, with six replications during each year. Total harvest time and handling time during harvesting were measured manually using a stopwatch. Berries harvested during each replication were weighed using an electronic industrial weighing scale (M1, Western Scale Co. Ltd., Port Coquitlam, BC, Canada) at a privately-owned wild blueberry receiving shed in Debert, Nova Scotia. During each replication, conditions were visually classified as either weedy or non-weedy. Weedy conditions were determined to be areas of more than $25 \%$ weed coverage and occurred primarily towards the outer extents of the three fields. All three fields saw similar weed profiles with narrowleaf goldenrod (Euthamia graminifolia L. Nutt.) being the predominant weed towards the outer extents of the fields and hair fescue (Festuca filiformis) and tickle grass (Agrostis scabra) being scattered throughout the inner portions.

All statistical analyses were performed using Minitab 19 (Minitab Inc., New York, NY, USA) using two-sample $t$-tests. All data was checked for normality and constant variance prior to analysis.

\section{Results and Discussion}

\subsection{Comparison of 2017 and 2018 Data}

Using a two-sample t-test it was determined that the mean harvest times in 2017 and 2018 were significantly different for both the small box handling system $(p=0.015)$ and the semi-automated bin handling system $(p<0.001$; Table 3$)$.

Table 3. Mean harvesting times for a $2.00 \mathrm{~h}$ period for both the small box handling system and the semi-automated bin handling system for 2017 and 2018.

\begin{tabular}{cc}
\hline Year and Harvester Handling System & Mean Harvesting Time (h) \\
\hline 2017 Small Box & $1.45 \pm 0.04$ \\
2018 Small Box & $1.51 \pm 0.03$ \\
2017 Semi-Automated Bin & $1.77 \pm 0.04$ \\
2018 Semi-Automated Bin & $1.96 \pm 0.02$ \\
\hline
\end{tabular}


All data was determined to be normally distributed and constant variance was not violated in any of the samples when using a residuals plot. The observed difference can most likely be attributed to the significant difference in terms of yield between 2017 and $2018(p<0.001)$ which resulted in more time between needing to offload full boxes and bins. As a result, data was analyzed separately for the 2017 and 2018 harvesting seasons.

\subsection{Berry Harvest Time and Handling Time}

In comparing within year and between handling systems, it was determined that there was a significant difference in terms of harvest time for the small box and semi automated systems in $2017(p<0.001)$ and $2018(p<0.001)$. In both cases, the semi-automated bin handling system outperformed the small box handling system. This result is encouraging, as it suggests that significantly more time can be dedicated to harvesting when using the semi-automated bin system compared with the significantly greater handling time of the small box system. In 2017 the semi-automated bin handling system resulted in a 55\% reduction in total handling time while in 2018 this number improved to a $68 \%$ reduction in total handling time. All of this means that harvester operators can harvest more land in less time and generate greater profit through reduced fuel consumption and labor costs. Additionally, the short harvesting window of the wild blueberry crop means that on larger operations, growers may not have time to harvest all of their crop before spoilage occurs. Use of the semi-automated bin handling system could help to alleviate much of this pressure.

In comparing within year and between handling systems, it was determined that there was a significant difference in terms of handling time for $2017(p<0.001)$ and 2018 $(p<0.001)$. In both cases, handling time was significantly lower for the semi-automated bin handling system. A full breakdown of handling time for both systems can be observed in Table 4.

Table 4. Breakdown of total handling time for 2017 and 2018.

\begin{tabular}{ccc}
\hline Handling Component & Small Box Handling (h) & $\begin{array}{c}\text { Semi-Automated Bin } \\
\text { Handling Time (h) }\end{array}$ \\
\hline 2017 & $0.56 \pm 0.04$ & \\
Total Handling Time & $0.17 \pm 0.01$ & $0.25 \pm 0.04$ \\
Loading Bin/Box Time & $0.39 \pm 0.04$ & $0.10 \pm 0.01$ \\
Unloading Bin/Box Time & & $0.15 \pm 0.03$ \\
\hline 2018 & $0.49 \pm 0.04$ & \\
Total Handling Time & $0.15 \pm 0.01$ & $0.16 \pm 0.03$ \\
Loading Bin/Box Time & $0.34 \pm 0.04$ & $0.05 \pm 0.01$ \\
Unloading Bin/Box Time & & $0.11 \pm 0.03$ \\
\hline
\end{tabular}

It should be noted that while time spent clearing debris from the harvester is included in handling time, this component never exceeded the time required to load and unload boxes. Clearing debris was always performed in parallel with loading and unloading and therefore it does not appear in Table 4.

\subsection{Effect of Weed Coverage on Berry Harvest and Handling Time}

Weed coverage, when classified as either high or low, did not have a significant impact on harvest time in either $2017(p=0.694)$ or $2018(p=0.765)$. Likewise, handling time was not significantly impacted by weed coverage in $2017(p=0.778)$ or $2018(p=0.976)$. These results are somewhat surprising as operators observed more weeds and debris making their way into the bins and boxes when harvesting in high weed conditions. Additionally, operators observed more weeds binding up in the teeth and housing of the harvester head which had to be periodically cleaned out. However, the results suggest that the time spent dealing with the additional weeds did not result in reduced efficiency when compared with low weed conditions. This is likely since the period spent loading and unloading bins and 
boxes is typically much longer than the period spent cleaning debris from the harvester. As these two tasks are typically performed in parallel, the additional weed build up did not result in a significant difference in handling time. That said, the weeds do create an additional task for the operator which in some instances could impact efficiency. It is equally important to note that harvest speed was maintained at a consistent $0.31 \mathrm{~m} \mathrm{~s}^{-1}$ regardless of weed coverage meaning that, harvest time shouldn't be significantly different provided berry yield is the same. However, when comparing berry yield by weed coverage, it was determined that significantly more berries were harvested under low weed conditions than high weed conditions both in $2017(p=0.011)$ and in $2018(p=0.045)$. Therefore, it is reasonable to suggest that the additional weed debris which collected in bins and boxes while harvesting in high weed conditions accounted for the reduction in harvestable yield when it came to the rate at which bins and boxes were filled. Therefore, while harvest time and handling time are not impacted by weed coverage, harvested berry yield is. It has also been noted that berry yield and picking efficiency is impacted by weed buildup in the harvesting teeth [25]. This factor could potentially be impacting the berry yields observed under high weed treatments.

\subsection{Harvest Rate}

Harvest rate was significantly improved for the semi-automated bin handling system both in $2017(p<0.001)$ and $2018(p<0.001)$ when compared with the small box handling system. Mean values for these harvesting rates can be observed in Table 5 .

Table 5. Mean harvest rates for both harvester handling systems for 2017 and 2018.

\begin{tabular}{cc}
\hline Year and Harvester Handling System & Mean Harvesting Rate (h/ha) \\
\hline 2017 Small Box & $7.22 \pm 0.19$ \\
2018 Small Box & $6.89 \pm 0.18$ \\
2017 Semi-Automated Bin & $5.89 \pm 0.10$ \\
2018 Semi-Automated Bin & $5.33 \pm 0.04$ \\
\hline
\end{tabular}

These results make sense given that the significant differences observed in harvest time over the two-hour sample period. The significant reduction in harvest rate means that harvester operators can harvest more cropland in less time using the semi-automated bin handling system when compared with the small box handling system. As discussed, this is largely due to the reduced handling time with the semi-automated system.

Similar to harvest time, weed coverage did not have a significant impact on harvest rate in either $2017(p=0.754)$ or $2018(p=0.737)$ at a consistent harvesting speed of $0.31 \mathrm{~m} \mathrm{~s}^{-1}$.

Comparing these findings with those in other cropping systems, we can see how a similar move towards enhanced mechanization has improved efficiencies. Zhang et al., 2016 developed a low-cost apple harvest-assist unit to replace ladders when picking [26]. Their units were able to improve harvest efficiency by $22 \%$ when compared with harvesting on a ladder. Across a variety of commodities, mechanized trunk shakers have proven to increase harvest efficiency by $15 \%$ over manual shaker techniques [27]. Use of a mechanized system in litchi harvesting improved efficiency by $1.55 \mathrm{~kg} \mathrm{~min}^{-1}$ over traditional hand harvesting, an improvement of $267 \%$ [28]. In highbush blueberries, efficiency improvements of up to 20 times have been seen when comparing mechanical harvesters to hand picking $[29,30]$. Comparing the results of our study to hand raking in wild blueberry yields a similar story, where a single hand raker averages $44 \mathrm{~h} \mathrm{ha}^{-1}[5,31]$. This means that a one double headed DBE wild blueberry harvester with a bin handling system can replace 8.25 laborers hand raking. There is the further benefit that harvester operators can also work longer hours, averaging a ten hour harvest day, whereas hand rakers typically average six [5]. If you factor in these increased hours, the DBE harvester can replace 13.83 laborers hand raking. For an industry which struggles to find enough laborers on a yearly basis, this labor savings is critical to the success of the crop moving forward. 


\section{Conclusions}

Wild blueberry farmers are currently facing farm labour shortages and rising labour wages which have increased overall wild blueberry harvesting costs. Wild blueberry farmers in Atlantic Canada, Quebec and Maine are seeking alternatives to the traditional small box handling system, such as the semi-automated bin handling technology. In this study, field capacity and harvest performance were quantified and compared for wild blueberry mechanical harvesters with both the small box and semi-automatic bin handling systems with double-head harvester configurations. Harvest time, box handling time and harvest rate data were used to quantify and compare the harvest efficiency of the two harvest handling systems. For both 2017 and 2018, the semi-automatic bin handling system demonstrated statistically improved harvest time and harvest rate. The effect of weed coverage on these same parameters was not significant though the effect of weed coverage on yield was shown to have a significant effect. In conclusion, the semi-automated bin handling system was a significant improvement on the small box handling system from a harvesting efficiency standpoint. In 2017, the semi-automated bin handling system resulted in a 55\% reduction in total handling time while in 2018 this number improved to a $68 \%$ reduction in total handling time. This reduction in handling time resulted in an $18.5 \%$ increase in overall harvest efficiency in 2017 and a $22.7 \%$ increase in 2018. In all, the findings of this research demonstrate the superiority of the bin handling system from a handling time and harvest efficiency standpoint.

Author Contributions: Conceptualization, E.K.Y. and T.J.E.; methodology, A.H.K., E.K.Y., T.J.E. and Q.U.Z.; validation, A.H.K., E.K.Y., T.J.E., A.A.F., Q.U.Z., P.J.K. and C.B.M.; formal analysis, A.H.K., E.K.Y., T.J.E., A.A.F., Q.U.Z., P.J.K. and C.B.M.; investigation, A.H.K., E.K.Y., T.J.E., A.A.F., Q.U.Z., P.J.K. and C.B.M.; resources, E.K.Y. and T.J.E.; data curation, A.H.K., E.K.Y., T.J.E., A.A.F., Q.U.Z., P.J.K. and C.B.M.; writing-original draft preparation, A.H.K., E.K.Y., T.J.E., A.A.F., Q.U.Z., P.J.K. and C.B.M.; writing—review and editing, A.H.K., E.K.Y., T.J.E., A.A.F., Q.U.Z., P.J.K. and C.B.M.; visualization, A.H.K., E.K.Y. and T.J.E.; supervision, E.K.Y., T.J.E., A.A.F. and P.J.K.; project administration, E.K.Y., and T.J.E.; funding acquisition, T.J.E. and Q.U.Z. All authors have read and agreed to the published version of the manuscript.

Funding: This research was financially supported by the following grant sources: Doug Bragg Enterprises and Natural Sciences and Engineering Research Council of Canada (NSERC) CRD Grants Program, NSERC Discovery Grants Program (RGPIN-06295-2019) and New Brunswick CAP.

Acknowledgments: This research was supported by Doug Bragg Enterprises Ltd., Natural Sciences and Engineering Research Council (NSERC), New Brunswick CAP, and Wild Blueberry Producers Association of Nova Scotia. The authors would like to thank Stephen Bragg (President, Doug Bragg Enterprises Ltd.) for providing harvester and bin handling system during the study, and Joe Slack (president, Slack Farms) for field use and help during data collection. The authors would also like to thank Dalhousie's Precision Agriculture and Mechanized Systems Research Team for help with field data collection.

Conflicts of Interest: The authors declare no conflict of interest.

\section{References}

1. Hall, I.V.; Aalders, L.E.; Nickerson, N.L.; Vander Kloet, S.P. Biological flora of Canada. 1. Vaccinium angustifolium Ait.; sweet lowbush blueberry. Can. Field Nat. 1979, 95, 415-430.

2. Kinsman, G. The History of the Lowbush Blueberry Industry in Nova Scotia 1950-1990; Nova Scotia Dept. of Ariculture \& Marketing: Truro, NS, Canada, 1993.

3. Eaton, L.J.; Nams, V.O. Second cropping of wild blueberries-Effects of management practices. Can. J. Plant Sci. 2006, 86, 1189-1195. [CrossRef]

4. Yarborough, D.E. Factors contributing to the increase in productivity in the wild blueberry industry. Small Fruits Rev. 2004, 3, 33-43. [CrossRef]

5. Yarborough, D.E. Progress towards the development of a mechanical harvester for wild blueberries. Vii Int. Symp. Vaccinium Cult. 2000, 574, 329-334. [CrossRef]

6. Ali, S.; Zaman, Q.U.; Farooque, A.A.; Schumann, A.W.; Udenigwe, C.C.; Esau, T.; Chang, Y.K. Potential use of digital photographic technique to examine wild blueberry ripening in relation to time of harvest. Appl. Eng. Agric. 2018, 34, 299-308. [CrossRef] 
7. Government of Nova Scotia. Minister Accepts Minimum Wage Increase Recommendations. 2019. Available online: https:/ / novascotia. $\mathrm{ca} /$ news / release/?id=20190108002 (accessed on 15 January 2019).

8. Esau, T.; Zaman, Q.; MacEachern, C.; Yiridoe, E.K.; Farooque, A. Economic and Management Tool for Assessing Wild Blueberry Production Costs and Financial Feasibility. Appl. Eng. Agric. 2019, 35, 687-696. [CrossRef]

9. Gallardo, R.K.; Zilberman, D. The economic feasibility of adopting mechanical harvesters by the highbush blueberry industry. HortTechnology 2016, 26, 299-308. [CrossRef]

10. Yarborough, D. Blueberry Crop Trends 1996-2017. In Proceedings of the Wild Blueberry Producers Association of Nova Scotia Annual General Meeting, Truro, NS, Canada, 17 November 2017.

11. Taylor, J.E.; Charlton, D.; Yúnez-Naude, A. The end of farm labor abundance. Appl. Econ. Perspect. Policy 2012, 34, 587-598 [CrossRef]

12. Gallardo, R.K.; Brady, M.P. Adoption of labor-enhancing technologies by specialty crop producers. Agric. Financ. Rev. 2015, 5, 514-532. [CrossRef]

13. Farooque, A.A.; Zaman, Q.U.; Groulx, D.; Schumann, A.W.; Yarborough, D.E.; Nguyen-Quang, T. Effect of ground speed and header revolutions on the picking efficiency ofa commercial wild blueberry harvester. Appl. Eng. Agric. 2014, 30, 535-546.

14. Metzger, H.B.; Ismail, A.A. Management Practices and Cash Operating Costs in lowbush Blueberry Production [Maine]; Life Sciences and Agriculture Experiment Station, University of Maine: Orono, ME, USA, 1976.

15. Bragg, C.; Doug Bragg Enterprises, Collingwood Corner, NS, Canada. Personal communication. 2019.

16. Khan, A.H.; Yiridoe, E.K.; Esau, T.J.; Koto, P.S.; Zaman, Q.U.; Farooque, A.A. Economic Comparison of Traditional Small Box and Semi-Automatic Bin Handling Harvesting Technologies for Wild Blueberries from a Field Trial: A Stochastic Approach. J. Agribus. 2020, 38, 117-146.

17. Faulkner, W.B.; Wanjura, J.D.; Boman, R.K.; Shaw, B.W.; Parnell, C.B. Evaluation of modern cotton harvest systems on irrigated cotton: Harvester performance. Appl. Eng. Agric. 2011, 27, 497-506. [CrossRef]

18. Harrigan, T.M. Time-motion analysis of corn silage harvest systems. Appl. Eng. Agric. 2003, 19, 389. [CrossRef]

19. Erdoğan, D.; Güner, M.; Dursun, E.; Gezer, I. Mechanical harvesting of apricots. Biosyst. Eng. 2003, 85, 19-28. [CrossRef]

20. Polat, R.; Gezer, I.; Guner, M.; Dursun, E.; Erdogan, D.; Bilim, H.C. Mechanical harvesting of pistachio nuts. J. Food Eng. 2007, 79, 1131-1135. [CrossRef]

21. Hanna, M. Estimating the Field Capacity of Farm Machines; Ag Decision Maker Information Files; Iowa State University: Ames, IA, USA, 2016.

22. Willcutt, H.; Barnes, E. Fuel consumption in spindle picker cotton harvesting systems. In Proceedings of the Beltwide Cotton Conferences, Nashville, TN, USA, 8-11 January 2008.

23. Schmitz, A.; Seckler, D. Mechanized agriculture and social welfare: The case of the tomato harvester. Am. J. Agric. Econ. 1970, 52, 569-577. [CrossRef]

24. Kay, R.; Edwards, W.; Duffy, P. Farm Management, 8th ed.; John Wiley and Sons: Hoboken, NJ, USA, 2016.

25. Esau, K.; Esau, T.; Zaman, Q.; Farooque, A.; Schumann, A. Effective use of a variable speed blower fan on a mechanical wild blueberry harvester. Appl. Eng. Agric. 2018, 34, 831-840. [CrossRef]

26. Zhang, Z.; Heinemann, P.H.; Liu, J.; Schupp, J.R.; Baugher, T.A. Design and field test of a low-cost apple harvest-assist unit. Trans. ASABE 2016, 59, 1149-1156.

27. Erkan, M.; Dogan, A. Harvesting of horticultural commodities. In Postharvest Technology of Perishable Horticultural Commodities; Elsevier: Amsterdam, The Netherlands, 2019; pp. 129-159.

28. Wang, W.; Lu, H.; Mo, C.; Yang, Z.; Hohimer, C.J.; Qiu, G. Experiments on the mechanical harvesting of litchi and its effects on litchi storage. Trans. ASABE 2017, 60, 1529-1535. [CrossRef]

29. Hu, B.; Yang, W.Q.; Andrews, H.; Li, C.; Takeda, F. Towards a semi-mechanical harvesting platform system for harvesting blueberries with fresh-market quality. Xi Int. Vaccinium Symp. 2016, 1180, 335-340. [CrossRef]

30. Takeda, F.; Yang, W.Q.; Li, C.; Freivalds, A.; Sung, K.; Xu, R.; Hu, B.; Williamson, J.; Sargent, S. Applying new technologies to transform blueberry harvesting. Agronomy 2017, 7, 33. [CrossRef]

31. Marra, M.C.; Woods, T.A.; Parker, R.; San, N.N.; Teisl, M.F. B825: A Comparison of Lowbush Blueberry Harvesting Technologies: Experimental and Economic Results from the 1988 Field Tests in Washington County, Maine; The University of Maine: Orono, ME, USA, 1989. 